\title{
Truth and Argument Evaluation
}

\section{PATRICK Bondy}

Department of Philosophy

McMaster University

1280 Main St. W.

Hamilton, $O N$

L8S 4 L8

Email:bondypr@mcmaster.ca
Resumé: Les buts de cet article sont de défendre l'idée que l'objectif des arguments est la vérité des jugements et de discuter du rôle que la notion de vérité joue dans l'évaluation des arguments. On conclut que la fonction juste de cette notion se trouve dans la métathéorie qui façonne une théorie d'évaluation, plutôt que dans une théorie d'évaluation qui est elle-même une limite sur la suffisance des prémisses.

Keywords: argument evaluation, rational acceptability, truth

\section{Introduction}

We are all familiar with the traditional conception of what makes for a good argument: that its premises are true and that it is valid, ${ }^{1}$ i.e. that a good argument is a sound argument. ${ }^{2}$ That traditional view of the goodness of arguments has sustained serious criticism over the past few decades, so that most theorists have dropped either the validity requirement or the truth requirement or both. Almost all theorists that I am aware of take it that an argument is good if it fulfills its purpose, and it is widely agreed that arguments can fulfill their purpose even when not all of their premises are true, or they are not deductively valid. Still, some theorists retain a focus on the truth-directed nature of arguments, and those theorists rightly hold that, given such a focus, truth plays an important role in the evaluation of arguments. Johnson (2000) goes so far as to

\footnotetext{
${ }^{1}$ At least, that is the core of the traditional view. Further constraints are typically added, such as that the argument not be question-begging.

${ }^{2}$ Hitchcock (1999) traces the concept of soundness in the textbook tradition to Black (1946), and before that (but with different terminology), to Cohen and Nagel (1934).

(c) Patrick Bondy. Informal Logic, Vol. 30, No. 2 (2010), pp. 142-158.
} 
reintroduce truth as a constraint on premise adequacy, alongside the criterion of acceptability, and he holds that in a case where a premise is false but acceptable, truth (/falsity) outweighs acceptability.

What I propose to do in this paper is to discuss the role that truth plays in the evaluation of arguments, when the purpose of arguments is understood as truth-directed in some important way. I begin with a discussion of truth as the purpose of arguments. In the second section of the paper, I give an argument to the effect that the theory of argument evaluation ought not to involve truth as a constraint on premise adequacy. The third section contains my argument for the positive claim that the proper place for the concept of truth is in the metatheory in terms of which the theory of evaluation is worked out. ${ }^{3}$ I conclude the essay with a response to the objection that deflationism about truth is incompatible with the conception of arguments as truth-directed.

\section{Truth as the purpose of (at least some) arguments}

The goodness of an argument, I take it, is a function of how well it fulfills its purpose. So, first of all, it must be admitted that there are many conceptions of the nature and purpose of arguments that do not involve persuading anyone of the truth of a conclusion: Walton (1998), Blair (2004), van Eemeren and Grootendorst (2004), Hitchcock (2006), and Pinto (2009), to name a few, all give accounts of argument on which truth is not the central purpose.

However, there is also a respectable contingent of thinkers that takes arguments to be directed towards truth. Goldman (1999, p. 156) views the "ultimate end" of good argumentation as true belief, although he admittedly restricts his position to ordinary factual arguments. Biro and Siegel take the "intrinsic goal, the raison d'être, of arguments" to be to "provide good reasons for belief," and they hold that a good argument is one that "provides reasons for believing that its conclusion is true" (2006, p. 94, italics in original). Finally, Johnson (2000, pp. 168, 181) takes the goal of arguments to be the rational persuasion of an Other (audience, interlocutor) of the truth of a claim.

I am inclined to endorse the view that the internal purpose of arguments - the purpose that they have just by virtue of being arguments, independently of the various further uses to which they

\footnotetext{
${ }^{3}$ By "theory of evaluation" I mean the set of criteria that a theory provides us with for evaluating arguments. By "the metatheory" in terms of which the theory of evaluation is worked out, I mean the broader theory of argument, including reference to what it is that the criteria for argument evaluation are supposed to accomplish, in which the theory of evaluation is articulated.
} 
can be put - is truth-directed. More specifically, I take the goal of the rational persuasion of an interlocutor or audience of the truth of a claim to be the best candidate for the general purpose of arguments, and arguments ought to be evaluated according to how well they fulfill that purpose. That is not to say that I take the purpose of arguments to be to establish the truth of their conclusions beyond all doubt; rather, the purpose is to reach a conclusion that is most rational, from the point of view of the participants in the argument, to take to be true.

My case for thinking that arguments are truth-directed, in a nutshell, is the following:

Premise 1. An essential part of the content of a proposition is its truth-conditions.

Premise 2. To assert a proposition (i.e., to assert some propositional content) is to assert that its truthconditions are satisfied. (From Premise 1.)

Premise 3. Assertions are always assertions of propositions.

Premise 4. Arguments consist of premises asserted in support of asserted conclusions. ${ }^{4}$

Conclusion: The conclusion of an argument is the assertion, on the basis of the premises, that the truth-conditions of the propositional content of the conclusion are satisfied. (From Premises 2, 3, and 4.)

I take it that Premises 1 and 3 are uncontroversial; Premise 3 is true by definition, and even arch-inferential-role-semanticist Robert Brandom has a place for truth-conditions and representation in his account of propositional content (see especially the discussion of the "broadly inferential" articulation of propositional content, in his (1994, Ch.2)), so Premise 1 looks safe. I expect that there are several objections that will come to mind, though, which I will try to answer presently.

First of all, it might be urged against Premise 2 that one might make an assertion without wanting to commit oneself to the claim that the truth-conditions of the asserted proposition are satisfied. For example, a scientist might make a claim about the singularity of a black hole (which is an unobservable entity-not even light can escape once it is within the black hole's event horizon),

\footnotetext{
${ }^{4}$ Another way to put this premise is to say that arguments are asserted conjunctions of the form "P1\&P2\&...Pn\&C\&(P1\&P2\&...Pn support C)." This way of putting the premise is fine, as long as we do not think of the final conjunct in the schema as playing the role of a premise in support of $\mathrm{C}$. It cannot play that role, on pain of incurring Carroll's famous regress (see Carroll 1895).
} 
without wanting to commit herself to the truth of the proposition that she is asserting, because its truth-conditions cannot in principle be verified.

By way of response to this objection, notice that if the scientist only means to commit herself to the claim that her assertion is consistent with the observed phenomena, then she is not in fact asserting a proposition about the singularity of the black hole itself -if she were, she would be committed to the truth of that proposition. Instead, she is making the more qualified assertion that the proposition she is putting forward is consistent with the observed phenomena. That is, she is making an assertion $q$ about a proposition $p$ (that $p$ is consistent with observed phenomena), not asserting $p$. That more qualified proposition, $q$, is one to which she is committing herself, and in so committing herself, she is committing herself to its truth.

A different way to push the objection to Premise 2, if we take the content of a proposition to be identical with its inferential role, is that someone might want to assert a proposition and only intend thereby to commit himself to those parts of the meaning of the proposition (i.e. those parts of its inferential role) that are not its truth-conditions. My response to this objection is to say that if someone wants to commit himself only to those parts of a proposition $p$ 's inferential role that are not its truth-conditions, then he is not asserting $p$ at all; he is making some other move in the language-game. However, if an arguer is explicit about intending to assert $p$, then whether he wants to be committed to the truth of $p$ is irrelevant. Assertions are public commitments; we are committed to the content of our assertions whether we like it or not, and that certain truth-conditions are satisfied is part of the content of an asserted proposition.

The second objection that I expect will naturally come up is against Premise 4. The objection is that not all arguments have asserted propositions as their conclusions. There are two ways to make this objection: either to hold that arguments can have conclusions that lack truth-values (for example, questions, as in (Hitchcock 2006)), or to allow that even though they must have truth-values, conclusions need not be assertions of the truth of a proposition. Reasons might be offered for doubting a proposition, for example, or for having some other attitude toward a proposition (as in Pinto 2009). Furthermore, the point of a reductio argument is not to assert the conclusion that is shown to follow from the assumed premises, but rather to reject a guilty premise or assumption. (Sometimes the author of a reductio argument will explicitly conclude with the assertion of the negation of one of the premises, but sometimes not.)

I admit that this objection has some force. An adequate 
response to it would likely take an entire paper to itself. It will have to suffice for now to remark that arguments that appear to have conclusions that have a truth-value but are not asserted can be viewed as having implicitly asserted conclusions. For example, in a reductio where it is not explicitly asserted as the conclusion that a guilty premise or assumption is to be rejected, there is an implicit conclusion to that effect. In the case of an argument that a proposition ought to be doubted, rather than accepted, we should take the conclusion of the argument to be of the form: "Assert: we should doubt that $p$." And if we are presented with a case where no asserted conclusion can sensibly be taken to be implicit, then it is not clear to me that we ought to call that an argument at all.

A final objection to the argument that I put forward above is that even if my argument is a good one, it does not establish what I want: I want to say that arguments are truth-directed, but all that the argument above shows is that arguments essentially involve the assertion of the truth of their conclusions. It does not show that arriving at the truth of the conclusion is the purpose of arguments.

On the face of it, though, it looks to me like the argument does support the view that arguments are truth-directed. If an argument is the assertion of premises in support of an asserted conclusion, and the assertion of a proposition essentially involves the assertion of its truth, it seems to follow that what we do in giving arguments is that we give reasons to think that the conclusion is true. The only way that I can think to object to this line of reasoning is to point out cases where arguments are used for purposes other than to show that their conclusions are true (for example, to simply get an issue on the table, to prove that one is very witty, etc.).

However, it does not follow from the fact that arguments can be used for many purposes that there is no central purpose of arguments. A hockey stick can be used, among other things, to defend oneself against a mugger, but that does not mean that the purpose of a hockey stick is to defend oneself against muggers, nor that the goodness of hockey sticks is to be measured by how well they can be used for that purpose. A good hockey stick is one that fulfills the particular function of hockey sticks well; even bad hockey sticks can serve other purposes well. Similarly, it does not follow from the fact that arguments can be used for various purposes that there is no central purpose of arguments - and if the particular purpose of arguments is to achieve rational persuasion of the truth of a proposition, then arguments ought to be evaluated according to how well they fulfill that purpose.

That concludes my case for taking arguments to be truthdirected. It is not necessary to agree with me about the general nature and purpose of arguments in order to accept the discussion of argument evaluation that appears in the following sections of the 
paper, though. Most theorists agree that some arguments, at least, aim to give good reasons to believe that their conclusions are true, and so sometimes, at least, arguments ought to be evaluated according to how well they achieve that goal. If you accept that arguments generally are truth-directed, then you can accept that the evaluative criteria that I will discuss will be perfectly general, applying to arguments across the board. If, on the other hand, you do not accept that general claim about the purpose of arguments, still the following discussion will be of interest as long as you accept that some arguments have that purpose, so that the truthdirected evaluation of arguments discussed below will apply to the subset of arguments that aim to show that their conclusions are true.

No doubt, before moving on, I owe an explanation of what I mean by "truth" when I say that arguments are truth-directed. I will not argue for the theory of truth that I have in mind, because there just is not the space to do so here (although I will respond at the end of the paper to an objection from the deflationist camp), but I want to be clear about the position I am advocating. By "true," I do not mean either verifiable or certain. Nor do I have in mind a relativist, pragmatist, or coherentist theory of truth. Rather, the account of truth that I have in mind is much like Goldman's descriptive-success (DS) theory, which is a version of the correspondence theory, on which an item (belief, statement, etc.) is true if and only if it purports to describe some portion of reality, and it successfully describes that part of reality (1999, p. 59). I think that Goldman's DS-account of truth succinctly captures the ordinary concept of truth. Given the DS-account of truth, the purpose of an argument is to rationally persuade an audience that the conclusion of the argument successfully describes that part of reality which it purports to describe.

Goldman restricts his discussion to ordinary factual argumentation (1999, p. 132), and so his theory of truth only needs to be able to accommodate truths that come up in such discourse; he neither asserts nor denies, as far as I know, that there even are truths in practical or aesthetic discourse. Now, I do think that there are truths in practical discourse, but that need not complicate the descriptive-success account of truth; it looks to me as though the account can easily cover practical as well as ordinary factual discourse. For example, the proposition " $S$ ought to $\phi$ " is true, on a descriptive-success account of truth, if and only if it successfully describes an obligation that $S$ has. Provided that there are real obligations (or, more generally, real practical imperatives), the descriptive-success account of truth can handle them, because real imperatives can be accurately or inaccurately described, just like ordinary facts can. If someone should object that there just are no 
truth-makers for practical claims, the response that I will want to give is that whatever it is that generates obligations (or practical recommendations generally) is what makes the propositions about them true. ${ }^{5}$ So I take it that Goldman's descriptive-success theory can apply to both practical and factual discourse. ${ }^{6}$

\section{Premise adequacy: acceptability, not truth}

The question on the table now is what the appropriate criteria for evaluating arguments are, when we view arguments as aiming to rationally persuade an audience of the truth of a conclusion. Perhaps the most natural place to start is with the requirement that an argument's premises be true. Johnson (2000) argues that premise truth ought to be included in the set of criteria that we employ for evaluating arguments, alongside of premise acceptability. He admits that there are good reasons for not employing the truth criterion in the evaluation of arguments, but he argues that there are even better reasons for employing it. The main reasons for excluding the truth requirement are that it does not appear to be necessary for an argument to be good that all of its premises be true, and that logic ought to say something about premise adequacy, but logic has nothing to say about the truth of an argument's premises (Johnson 2000, pp. 196-197).

The reason Johnson gives for maintaining the truth requirement is that it is difficult to see how we could develop a theory of evaluation without having some recourse to it. Theorists who propose to do without the truth requirement either make use of it unofficially, or continue to rely on it by employing terms that presuppose a commitment to it, or else they use the truth requirement in their metatheory, employing it in the metalanguage in which they develop their account of argument evaluation

\footnotetext{
${ }^{5}$ One might object here that nothing generates practical imperatives. If that is the case, so be it - but that is no problem for the descriptive-success account of truth; practical claims will simply turn out to be false, in that case, because a practical claim says that something is the case (that we ought to be charitable, for example), but what it purports to be the case, is not (we have no obligations; $a$ fortiori, we have no obligation to be charitable, so any purported description of our obligation to be charitable is bound to be unsuccessful).

${ }^{6}$ I have to admit that I am less certain about how well Goldman's account of truth can handle aesthetic propositions, such as "Aristophanes's plays are more entertaining than Sartre's." However, my initial inclination is to say that it can handle them, in a manner analogous to the way that it can handle practical propositions: insofar as aesthetic propositions purport to describe something (which it seems to me that they do-to say of $x$ that it is funnier than $y$ is to describe their relative levels of humour, for example), and insofar as what they purport to describe can be accurately or inaccurately described, the descriptivesuccess account can handle them.
} 
(Johnson 2000, p. 197).

Given that Johnson takes the purpose of arguments to be rational persuasion of the truth of a claim, he also includes the requirement that a premise be both accepted by the audience and rationally acceptable to them. The idea here is that if a claim is not accepted by the audience, or if they do accept it but it is not rational for them to do so, then it cannot be used as a premise in an enterprise that aims to achieve rational persuasion. It might be an effective premise, if it plays to the emotions or biases of the audience, but the persuasion that ensues in that kind of case is not rational persuasion. The premises that an arguer employs must, then, either be supported themselves by a good argument, or else they must be such that it is rational for the arguer to believe that the audience will accept them, and also that it is in fact rational for the audience to accept them (Johnson 2000, pp. 194-195). (I would also add that it must be rational for the arguer to accept them as well. More about this below.)

In his discussion of the truth criterion, Johnson often talks in terms of a requirement (e.g. p. 195), which makes it sound like he is talking about a necessary condition for premise adequacy. At one point, though, in response to the argument that the truth of a premise is neither necessary nor sufficient for the premise to be adequate (a complaint that comes up, for example, in Pinto (1994) and Govier (1999, Ch. 7)), Johnson appears to be content with considering truth to be a standard, or criterion, that is neither necessary nor sufficient for premise adequacy $(2000$, p. 280). The truth of an argument's premises might be one important consideration, on this line of thought, which can be overridden by other factors, just as winning the most games in one season in Major League Baseball is neither necessary nor sufficient for winning the Cy Young Award, but it is an important consideration.

Presenting truth as a standard or criterion is more palatable than presenting it as a requirement, because examples of false but acceptable premises do not then count as counterexamples. However, I still have some misgivings about this weaker presentation of the truth criterion. First, whether an argument's premises are true does not seem to me to be an appropriate criterion by which to measure them, even on that weaker reading; and second, in cases where a premise is false but acceptable, Johnson privileges truth over acceptability (2000, pp. 339-340), so he seems to want truth to be a necessary condition for premise adequacy after all.

The reason I worry about privileging the truth of a premise over its acceptability in any kind of case is that premises that are acceptable (as opposed to merely accepted) are more suited to fulfilling the purpose of arguments: acceptable premises, 
remember, are those that are rational to accept. Just when a premise counts as acceptable is still an open question, I take it; Johnson (2000, pp. 194-195) puts forward the requirement that either a premise must be supported with good reasons, or else it must be such that the arguer takes it to be rational for the audience to accept without support. Freeman (2005) develops an account of acceptable premises, as premises for which there is a presumption in a dialectical situation. However the acceptability requirement is worked out in the end, though, it is clearly crucial for premise adequacy: if an argument is to provide rational support for the truth of its conclusion, its premises must be such that they are rational for the participants in the argument to accept, and whether the premises are true is an independent question from whether they are rational to accept, for the widely acknowledged reasons that we can have good reasons to believe false propositions, in unfortunate epistemic circumstances, and that we can have true beliefs that have little or no evidential support.

Admittedly, Johnson sometimes gives the impression, when he is arguing that we should privilege truth over acceptability, that what is really the issue is whether an arguer ought to employ premises that she takes to be true, or premises that the audience takes to be true (2000, pp. 336-340). To scant the details, it seems that Johnson sometimes (not always, but sometimes) wants to associate acceptability with the audience's perspective, and truth with the arguer's assessment of claims, and what he wants to avoid is the view that one may pander to an audience's beliefs, when one takes those beliefs to be mistaken. Johnson is correct, I take it, in wanting to say that an arguer may not employ premises that she believes to be false, but that requirement is better put in terms of the acceptability of a premise from the perspective of the arguer, rather than in terms of the truth of the premise. I see no reason to privilege the epistemic position of the arguer over that of the audience, by associating her perspective with the truth criterion; both arguer and audience are, in principle, equally well-placed to determine the truth of a premise. The same criterion ought to apply to each of their assessments of the truth of a claim, and the appropriate criterion (I am arguing) is acceptability. ${ }^{7}$

So, whatever we think of the status of truth in the evaluation of

\footnotetext{
${ }^{7}$ One might wonder how this appeal to the rational acceptability of a premise to both the arguer and the audience squares with the earlier discussion of the purpose of arguments, which involved an appeal only to the arguer's perspective. The short answer is that, because arguers (not audiences) construct arguments, it is the arguer's perspective to which we must appeal in establishing the purpose of arguments. But if the purpose of arguments is rational persuasion, then it is necessary that the premises of an argument be rational for both the arguer and the audience to accept; if that condition is not met, then any persuasion that might ensue will not be rational.
} 
premises, acceptability ought to be seen as a necessary condition of premise adequacy. What is more, acceptability also appears to be sufficient for premise adequacy: whenever a premise is rational for the participants in an argument to accept, it is an appropriate candidate for employment in an enterprise that aims to rationally persuade the audience of the truth of the conclusion (see Pinto 1994, pp. 118-119, for some similar remarks). There is nothing more that we ought to require for the adequacy of a premise than that it be rational to accept. Johnson writes that he sees no reason why we should not want our premises to be true as well as acceptable (2000, p. 337), and I think that there is something to that - after all, the point of restricting permissible premises to those that are rational to accept is that those are the ones that are most likely, from the point of view of the participants in the argument, to be true. Now, in an epistemically ideal world, all of the claims that are rational to accept would be true. In the actual world, what is rational to accept is not always what is true, but still the rational status of a proposition is the best indicator of whether we should take it to be true. Whenever a premise is rational for the participants in an argument to accept, then, it is a good premise to employ. The upshot of all of this is that acceptability is both necessary and sufficient for premise adequacy, which means that the truth of a premise is beside the point for premise adequacy; what matters is whether it is rational for the participants in the argument to take them to be true.

At this point, we might notice that to raise an objection against an argument on the grounds that its premises are false is perfectly legitimate, and the legitimacy of this kind of objection lends prima facie support to the truth requirement for premise adequacy. Now, I agree that if we are participants in an argument, then of course it is legitimate for us to object to the argument on the grounds that it has false premises (assuming, of course, that it is reasonable for us to believe that it has false premises) - and that legitimacy is captured by a theory of evaluation that only emphasizes premise acceptability just as well as it is by a theory that also requires the truth of premises. For a premise to be acceptable is for it to be rational to accept; if a participant in the argument has reason to believe that the premise is false, then the premise fails to be acceptable, and so may not be used (at least, not without further argument in support of the premise). In other words, the objection "but that premise is not true" is only a legitimate objection if the objector has some reason to deny its truth, in which case the premise fails to be acceptable.

The further objection that evaluative concepts like inconsistency presuppose commitment to the truth requirement (because inconsistency occurs when two or more claims cannot be 
true together) is not a problem for the acceptability-account of premise adequacy either. If an argument employs inconsistent premises, then either the participants in the argument recognize it, or not. If they do, then they have excellent reason to doubt that the premises can all be true. In such a case, even if someone is willing to accept the inconsistent premises, it cannot be rational for him to do so. On the other hand, if the participants in the argument, through no fault of their own, do not recognize the inconsistency of the premises (for example, if the premises are sufficiently complex that the inconsistency would take a lot of work to expose), then it can be rational for them to accept the inconsistent premise-set. Of course, if the participants do not recognize the inconsistency of the premises because of some rational failing on their part (laziness, perhaps), then it is clearly not rational for them to accept the premises. So it looks like the rejection of inconsistency does presuppose a commitment to the truth, but not to a truth criterion for premise adequacy; rational acceptability can do the job just as well.

So, to sum up the case for excluding the truth criterion: acceptability is both necessary and sufficient for a premise to be adequate to employ in an argument. Truth does not add anything when it is present, or take anything away when it is absent, so it ought not to be taken to be a criterion for premise adequacy.

\section{Where the truth properly lies: the metatheory of argument evaluation}

In this paper I am interested in the place of truth in the theory of argument evaluation for those arguments that are truth-directed. In the previous section I argued that we ought not to take truth to be a criterion for premise adequacy; in this section I want to argue that the proper place of truth is in the metatheory in terms of which the theory of evaluation is articulated. Recall Johnson's point that theorists who claim to disavow the truth requirement still make use of it, some by making unofficial use of it, others by using terms that presuppose commitment to it, and still others by making use of it in their metatheory. I take that third strategy to be exactly the one to adopt. I will not attempt to develop a theory of argument evaluation here, via a metatheory employing the concept of truth, but I will argue that that is the best approach, and I will also argue that it does not entail a truth criterion for premise adequacy.

The argument for the claim that the concept of truth must be employed in the metatheory in terms of which the theory of evaluation is articulated is very brief. First, I take it that arguments are truth-directed; they aim to rationally persuade someone of the 
truth of a claim. Even if I am wrong, though, and that is not the goal of all arguments, still it is the goal of at least some arguments, and it is those that I am interested in. The second premise is that arguments ought to be evaluated in terms of how well they fulfill their purpose. ${ }^{8}$ So, since rational persuasion of the truth of a proposition is the purpose I am interested in, truth will necessarily figure in the metatheory in terms of which the theory of evaluation will be articulated.

That argument, at least, appears to me to be both clear and cogent, so I will move on to the next point, which is that having a metatheory that employs the concept of truth does not entail that truth ought to be a constraint on premise adequacy in the theory of evaluation that is developed in the framework of that metatheory. The idea is that, given the truth-directed nature of the kind of arguments that I am interested in, the criteria of a good argument will be such that they will maximize the likelihood, from the point of view of the participants in the argument, that they will arrive at true conclusions. Because it is the rational persuasion of the truth of a conclusion that is the goal, emphasis must be placed on the conditions under which an argument appears to be rational to its participants.

As I have argued, when truth and rational acceptability come apart, acceptability matters more than truth, because what is rational to accept is what is most likely, from the point of view of the participants in the argument, to be true. The criteria by which arguments are to be evaluated, on this approach, gain their legitimacy by the way that they increase the likelihood ${ }^{9}$ that the argument will proceed in a rational manner from premises that are rational to accept to a conclusion that is rational to accept. So, even though the metatheory in terms of which the theory of evaluation is to be worked out is one that favours truth, it cannot place a direct constraint that the premises be true, because then it will undermine the rationality of the procedure in cases where truth and acceptability conflict.

I do not propose to develop a full theory of evaluation here,

\footnotetext{
${ }^{8}$ Goodwin (2007) rejects the view that functions can determine norms, on the ground that functions do not determine unique sets of norms - many different sets of norms can often serve the same function. This objection is a problem for those who want to establish that a particular set of norms is correct, by way of showing that they satisfy the function of arguments. The objection does not worry me, though, since my aim here is not to determine a unique, correct set of argumentative norms.

${ }^{9}$ Both from an objective point of view, a point of view emphasizing what really promotes the rational progression of the endeavour, as well as from the point of view of the participants in the argumentative exchange, since what makes for a good argument (what makes it likely that rational persuasion takes place) must be manifest to the participants.
} 
but I would like to note that the three criteria that Johnson advocates other than truth - the familiar criteria of relevance, sufficiency and acceptability-seem to me to fit well in a metatheory that privileges the rational persuasion of the truth of a conclusion. (I take it that I have already said enough about acceptability.) Relevance of a premise-set to its conclusion is clearly important for an argument to fulfill its purpose: although we are still arguably in need of a sustained theory of relevance, it is clear at least that if the premises of an argument are to persuade anyone rationally to accept the truth of a conclusion, they must bear on the truth (or acceptability) of the conclusion. That is to say, they must be relevant. Sufficiency is also key, because if there is not enough support for the conclusion, then (almost by definition) it cannot be rational to accept the truth of the conclusion on the basis of the premises offered.

That set of criteria is not, of course, the only candidate for a truth-oriented theory of evaluation. Goldman (1999, pp. 134-144), for one, offers a set of fourteen explicitly truth-oriented criteria, and I see no prima facie reason to doubt their usefulness (except perhaps for Goldman's explicit proviso that he is only concerned with factual, not practical, arguments, whereas I am interested in arguments generally). I do not mean to adjudicate between Johnson's and Goldman's approaches here, or to suggest that theirs are the only ones available, but only to point out that there are several kinds of approach that a truth-oriented theory of evaluation could adopt.

\section{Concluding remarks on deflationism}

The only thing left to do now is to answer an objection that comes out of a deflationary view of truth. The objection is that only a deflationary account of truth can work, and that deflationism is incompatible with viewing any arguments as truth-directed. Hamblin (1970), for example, argues that truth has no role to play in argumentative situations, and his reasons for thinking so appear to be deflationist in spirit. He argues, for example, that in asserting " $p$ is true," a speaker $\mathrm{S}$ might just as well have asserted " $p$ " or "I accept $p$ " (p. 243). The equivalence of " $p$ " and " $p$ is true" is one of the central claims made by deflationists, so Hamblin might be seen as lodging a deflationist objection to the claim that truth has any role to play in arguments.

However, there are two things to say about Hamblin's case here. First of all, without going into any great exegetical detail, let me point out that Hamblin takes truth to be an onlooker's concept (1970, p. 242) - and onlookers presumably have something substantive in mind when they employ it - and that he gives a 
sustained hearing to both epistemic and alethic criteria for argument evaluation. He does not appear, therefore, to be a deflationist about truth. The second thing to say about Hamblin's claim is that, as Johnson notes $(2000$, p. 279), " $p$ is true" is made true by whatever $p$ is about, whereas "I accept $p$ " is made true by one's propositional commitments. The truth of $p$ does not reduce to anyone's acceptance of $p$.

We might still wonder, though: even if Hamblin's case here won't work, doesn't a thoroughgoing deflationism about truth undermine the view that arguments are truth-directed? I have to say that I am not convinced that a correspondence theory of truth cannot work, but deflationism is a serious contender among the available theories of truth, so this is an important objection to answer. Fortunately, deflationism appears to me to be compatible with viewing arguments as truth-directed.

It is difficult to say precisely what deflationism is, because deflationism does not have a single, or even a central, set of doctrines that all deflationists accept. Characteristic of the deflationist spirit is the attempt, first, to build a theory of truth around the T-schema: " $p$ " is true if and only if (iff) $p ;{ }^{10}$ and second, to keep the theory from having any serious metaphysical commitments. Beyond those foundations, theories diverge. However, I can say that I find the deflationist account of truth offered by Hill (2002) appealing, and it, at least, is not threatening to the truth-directed conception of arguments.

The bare bones of Hill's account are as follows:

(S) for any $x, x$ is true iff there is some $p$ such that $((x=$ the thought that $p$ ) and $p$ ) (p.22);

(SC) for any thought $x$ and any state of affairs $y, x$ semantically corresponds to $y$ iff there is some $p$ such that ( $x=$ the thought that $p$ and $y=$ the state of affairs that $p$ ) (p.49). ${ }^{11}$

(S) is the heart of Hill's substitutionalist account of truth. It is in effect a transformation of the T-schema into a universally quantified proposition. (SC) is intended to capture the semantic

\footnotetext{
${ }^{10}$ It will be easiest here to take the left-hand side of the T-schema to refer to the proposition (rather than the sentence) that $p$, and the right-hand side to the state of affairs that $p$.

${ }^{11}$ Hill defines the quantifiers in these principles not in semantic fashion, but in terms of rules of inference (2002, pp. 18-19). That avoids the circularity that would otherwise arise in defining truth with the use of quantifiers that are themselves defined in terms of truth. (I should also note that, for ease of exposition, I am only very closely paraphrasing Hill's principles.)
} 
correspondence between thoughts and possible states of affairs that (S) appears to require. In each of these principles, "thought" means "proposition".

Hill's account of truth is compatible with a truth-directed conception of arguments. On a descriptive-success account of truth like Goldman's, recall, the purpose of an argument is to rationally persuade the audience that its conclusion successfully describes the portion of reality that it purports to describe. On a deflationist account like Hill's, the purpose would instead be to rationally persuade the audience that the state of affairs that semantically corresponds to the argument's conclusion is actual. If an argument succeeds in doing that, then it succeeds in rationally persuading the audience that its conclusion is true. These two ways of conceiving of the truth-directed nature of arguments are in fact quite similar, except that Hill's account makes do without the notion of a description of reality.

It might seem, though, that because Hill makes use of the relation of semantic correspondence, his account is not really deflationist. However, it looks to me as though what he calls "semantic correspondence" is already present in the T-schema, which is the starting-point of deflationary theories. The two sides of the biconditional in any substitution instance of the T-schema share propositional content; that shared content explains why we accept the T-schema in the first place. If the two sides of the biconditional did not share that content, we would not have any good reason to accept all normal substitution instances of the Tschema. That shared content is all that the relation of semantic correspondence is meant to capture.

"Semantic correspondence" is perhaps an unfortunate term, as it makes the theory sound like a more traditional correspondence theory of truth - indeed, the (SC) principle is intended to capture ordinary correspondence intuitions about truth, but the principle achieves that goal without committing to a full-blown correspondence theory. The notion of semantic correspondence is quite thin; all it aims to capture is that it is the proposition that $p$ that is true whenever the state of affairs that $p$ obtains. The account still appears to be properly deflationist, then, so there is at least one deflationist account of truth that is compatible with the truthdirected conception of arguments.

However, if the notion of semantic correspondence is still too much for a thoroughgoing deflationist to accept, then it seems to me that we could resort to recasting the remarks in this paper about the purpose of arguments as rationally persuading an audience of the truth of $p$ into the claim that the purpose of arguments is to rationally persuade an audience of whether $p$, because on a deflationist account, " $p$ " is equivalent to " $p$ is true." The claim that 
rational acceptability outweighs truth in the determination of good premises can be recast as the claim that the rational acceptability of a premise $p$ outweighs whether $p$. And so on.

So, to sum up: arguments are to be evaluated in terms of how well they fulfill their purpose; in at least some cases, that purpose is to achieve rational persuasion of the truth of a proposition; so in those cases, arguments are to be evaluated according to whether they achieve such persuasion. Truth does not figure in the criteria that we ought to use to determine whether rational persuasion has taken place; its place is in the metatheory in terms of which the criteria for evaluating arguments are to be worked out. And the objection that the correspondence theory of truth that I prefer to work with is an untenable conception of truth-that only a deflationist account can work - is not a serious objection, because deflationism is compatible with the view of arguments as truthdirected.

Acknowledgments: I would like to thank David Hitchcock, Eric Krabbe, and Paul Simard Smith, as well as two anonymous Informal Logic referees, for their invaluable feedback on earlier drafts.

Editors' Note: This article is the revised version of a paper that was co-winner of the Association for Informal Logic and Critical Thinking (AILACT) Essay Prize for 2009.

See: http://ailact.mcmaster.ca/ep_call.html

\section{References}

Biro, John, and Harvey Siegel. (2006). "In Defense of the Objective Epistemic Approach to Argumentation." Informal Logic. vol.26, no.1, pp.91-101.

Black, Max. (1946). Critical Thinking: an Introduction to Logic and Scientific Method. New York: Prentice-Hall.

Blair, J. Anthony (2004). "Argument and Its Uses." Informal Logic. vol.24, no.2, pp.137-152.

Brandom, Robert. (1994). Making it Explicit. Cambridge, Mass: Harvard University Press.

Carroll, Lewis. (1895). "What the Tortoise said to Achilles." Mind. vol.4, no.14, pp.278-280.

Cohen, M.R. and Ernest Nagel (1934). An Introduction to Logic and Scientific Method. Simon Publications, Inc. 
Eemeren, Frans H. van, and Rob Grootendorst. (2004). A Systematic Theory of Argumentation: the Pragma-Dialectical Approach. Cambridge, New York: Cambridge University Press.

Freeman, James B. (2005). Acceptable Premises: an Epistemic Approach to an Informal Logic Problem. Cambridge, New York: Cambridge University Press.

Goldman, Alvin. (1999). Knowledge in a Social World. Oxford: Clarendon Press of Oxford University Press.

Goodwin, Jean. (2007). “Argument Has No Function." Informal Logic. vol.27, no.1, pp.69-90.

Govier, Trudy. (1999). The Philosophy of Argument. Newport News, VA: Vale Press.

Hamblin, C.L. (1970). Fallacies. Newport News, VA: Vale Press.

Hill, Christopher. (2002). Thought and World: an Austere Portrayal of Truth, Reference, and Semantic Correspondence. Cambridge, UK: Cambridge University Press.

Hitchcock, David. (1999). "The Origin of the Technical Use of 'Sound Argument': a Postscript." Informal Logic, vol.19, pp.213-214.

Hitchcock, David. (2006). "Informal logic and the concept of argument." In Dale Jacquette (Ed.), Philosophy of Logic, volume 5 of Dov M. Gabbay, Paul Thagard and John Woods (Eds.), Handbook of the Philosophy of Science. Elsevier. pp. 101-121.

Johnson, Ralph H. (2000). Manifest Rationality: A Pragmatic Theory of Argument. Mahwah, NJ: Erlbaum.

Pinto, Robert C. (2009). "Argumentation and the Force of Reasons.” Informal Logic. vol.29, no.3, pp.268-295.

Pinto, Robert C. (1994). "Logic, Epistemology and Argument Appraisal." In New Essays in Informal Logic. Windsor, ON: Informal Logic, pp.116-124.

Walton, Douglas. (1998). The New Dialectic: Conversational Contexts of Argument. Toronto, Buffalo, London: Toronto University Press. 